\title{
Evaluate\& Analysis of Single Cylinder Diesel Engine By Using Sesame Oil Blend's With Diesel
}

\author{
Dr.S.V.Saravanan ${ }^{1}$, Prof.L.Suresh ${ }^{2}$, K.P.Shankar ${ }^{3}$, R.Veeramani ${ }^{4}$, \\ S.Malarvannan ${ }^{5}$
}

\begin{abstract}
The interest in alternative fuels increases continuously in order to meet the growing demand for energy and protect the environment. A successful alternative fuel meets the environmental and energy security needs without operational performance. One of the most successful alternative fuels is biodiesel, which is always attention in today's world. Operationally, biodiesel blends perform very similar to conventional diesel in terms of performance and emissions without major changes in the engine, because the properties of biodiesel and conventional diesel are similar. In the present work, biodiesel is made from sesame oil and short-term tests were conducted with various mixtures of diesel and biodiesel in a single-cylinder four-stroke diesel engine and power and rated emissions and engine operation.
\end{abstract}

\section{INTRODUCTION}

As the global debate is less dependent on fossil fuels, alternative fuels heated debate on the rise. One of the most frequently mentioned in the bio-diesel, the $100 \%$ liquid fuels from agricultural sources, often referred to as B100. In general, biodiesel is used as fuel for diesel vehicles can use biodiesel fuel oil, sesame oil. Biodiesel is made from pure vegetable oils, waste cooking oil or waste animal fats and oils. It may be used alone or mixed with petroleum diesel in any percentage without major modifications to the engine.

The raw material for biodiesel production may vary from country to country, depending on the availability of certain vegetable oils. For example, vegetable oils such as soybean oil in the United States, Europe, rapeseed oil, palm oil used in Malaysia and India Jatropha biodiesel are compression-ignition fuel.

Transport sector in Bangladesh is mainly used for gasoline, diesel and compressed natural gas (CNG). There are estimates that the natural gas resources becoming scarce and actually reached its low point in 2020 may be imposed. At present, Bangladesh imported 2.4 million tons of diesels per year.

The total amount in Kuwait, Saudi Arabia, the United Arab Emirates and India, the value of imported goods is more than $\$ 2$ billionth The demand for diesel fuel is about 15 percent in recent months has increased the increased use of captive generators in the industry, businesses and homes, as the country is affected by the outage. The higher consumption of diesel, which is about 60 per cent of the total imports of petroleum products, it creates a new Kraftstoffdruckauf import bill of the country in this business. Diesel is also used in irrigation pumps and the transport sector. To meet the growing demand for diesel, biodiesel can be an alternative source. The production of oilseeds such as mustard, peanuts - , linseed oil, castor oil - coconut, sesame and as 384,115 tons / year, which produced about 11,000 megatons of sesame / year. This number is not sufficient for the production of biodiesel in the sesame oil in Bangladesh. More sesame seeds can be considered a huge unused land that approximately 0,320,000 acres, and in this case, sesame accounts also grown as an alternative source for biodiesel production. Sesame oil mainly consists of triglycerides of saturated single oleic acid ( 43\%) , twice with saturated linoleic acid ( 35\%), palmitic acid ( $11 \%$ ) and stearic acid ( $7 \%$ ). Due to its excellent antioxidant properties, sesame excellent personal life. In addition, there is a non-drying oil and a highly stable rarely turning rancid in hot climates.

The methanol produced in the present work biodiesel sesame oil base - catalyzed transesterification reaction. Effect of different reaction parameters, such as examining the molar ratio methanol / oil and the catalyst concentration and the optimal parameters have been found. Transesterified kinetics were examined and proposed a pseudo -first-order kinetic equation. Experimental data were fitted to the model.

\section{MATERIALS AND METHODS}

\subsection{Chemicals}

Methanol ( $99-100 \%$ ), ethanol ( 99-100\%) and sodium hydroxide pellets $(96 \%)$, potassium hydroxide pellets ( > 84\%), phenolphthalein ( $\mathrm{pH} 8.2$ to 9.8 ), the starch, acetone ( $99 \%$ ), benzene , sodium thiosulfate ( $99.0 \%$ ), n- hexane ( $96 \%$ ) hydrochloric acid ( $37 \%)$, sulfuric acid $(98 \%)$, isopropanol , iodine, sodium iodide, acetic acid - bromine, carbon tetrachloride, phosphoric acid (85\%) - and - Diphenylcarbazide , potassium dichromate, etc. were purchased from Merck, Germany. The chemicals used in analytical purity. 


\subsection{Extraction of oil}

Sesame seeds were collected from the local market. Oil extracted from the seeds of the mechanical press. The vertical, hand-operated cylinder $(4.3 \mathrm{~cm} \mathrm{ID)}$ built a mechanical press that helical screw which conveys the bulk of the hoper to increase the pressure range. Slow and continuous rotation allows you to increase the pressure on the press to get enough oil. The mixing and distribution of the random Spiralschraubefür will be used. Oil outlet openings are arranged in the area of the plug. At first, the sesame seeds are crushed and shattered by the weight of oil extracted. $20 \mathrm{ml}$ of solvent (n-hexane), $50 \mathrm{~g}$ of crushed sesame mixed in this method, and then extracted from the oil seeds. After oil extraction was filtered and dried at $600 \mathrm{C}$, solvent was evaporated in a rotary vacuum evaporator. The content of sesame oil were $35 \%$ ( v/w ).

\subsection{Synthesis of biodiesel transesterification}

Biodiesel is synthesized sesame oil base - catalyzed transesterification. The reaction is carried out at 60 $0 \mathrm{C}$ and atmospheric pressure under reflux for 90 minutes with vigorous stirring. Typically, an oil sample, $50 \mathrm{~g}$, $250 \mathrm{~mL}$ round bottom flask equipped with a reflux condenser, a two neck. The flask was immersed in an oil bath with a temperature controller and a magnetic stirrer. Sodium hydroxide pellets (1\% oil) was dissolved in the required amount of methanol. Methanol is used in a molar ratio of 06:01 of the oil. Sodium - The meth oxide solution was transferred to the reaction flask. After 90 minutes the reaction was quenched by addition of the stoichiometric required amount of concentrated hydrochloric acid, and the contents are then cooled to room temperature. Once during the reaction, the reaction product is allowed to stand 12-14 hours in a separatory funnel. Three separate layers was observed. The upper layer was excess methanol, middle layer was a mixture of methyl ester (biodiesel) and the lower layer was soap, glycerol and the crude alkali catalyst. The biodiesel phase is separated, and the layer was opaque, because it contains some of the catalyst, methanol , triglycerides, and soap. Biodiesel sesame.

Properties of diesel oil, sesame oil and the methyl ester
\begin{tabular}{|c|c|c|c|c|}
\hline SL NO & $\begin{array}{c}\text { PROPERTIE } \\
\text { S }\end{array}$ & $\begin{array}{c}\text { DIESE } \\
\text { L }\end{array}$ & $\begin{array}{c}\text { SESAME } \\
\text { OIL }\end{array}$ & $\begin{array}{c}\text { BIODIESEL } \\
(\text { SOME) }\end{array}$ \\
\hline 1 & $\begin{array}{c}\text { Specific } \\
\text { gravity }\end{array}$ & 0.83 & 0.88 & 0.85 \\
\hline 2 & $\begin{array}{c}\text { Kinematic } \\
\text { Viscosity at } \\
40^{\circ} \mathrm{C}(\mathrm{cSt})\end{array}$ & 3.72 & 52.5 & 4.72 \\
\hline 3 & $\begin{array}{c}\text { Flash point } \\
\left({ }^{\circ} \mathrm{C}\right)\end{array}$ & 62.00 & 345 & 142.00 \\
\hline 4 & $\begin{array}{c}\text { Fire point } \\
\left({ }^{\circ} \mathrm{C}\right)\end{array}$ & 64.00 & 360 & 176.00 \\
\hline 5 & $\begin{array}{c}\text { Calorific } \\
\text { value (kJ/kg) }\end{array}$ & $\begin{array}{c}42500 . \\
00\end{array}$ & 39480.00 & 38480.00 \\
\hline 6 & Cetane No & 48.00 & 36.00 & 42.00 \\
\hline 7 & $\begin{array}{c}\text { Oxygen } \\
\text { Content }\end{array}$ & - & $11.60 \%$ & $11.60 \%$ \\
\hline
\end{tabular}

\section{Experimental set-up}

The engine at rated speed of $1500 \mathrm{rpm}$ surgery for all tests. For all tests, the engine is started with diesel fuel and stabilizes for 30 minutes. After the engine has warmed up, it is then to Nome diesel mixture Switched. For each experiment, three measurements are performed to determine the mean value of the data reproducibility of the data, and estimate the accuracy of the measurement. 


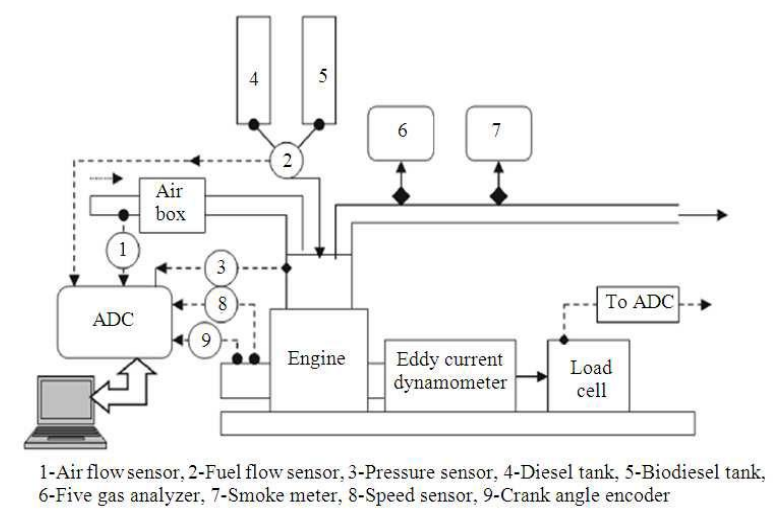

Upon completion of the test, the fuel switch back to diesel and engine running for a while held before shutdown to flush Nome diesel blends of fuel lines and fuel injection system . Performance accounts parameters such as brake thermal

Efficiency (BTE) and brake specific energy consumption (BSFC), combustion parameters such as cylinder pressure, heat release rate and emission parameters such as intensity, such as smoke - , HC, CO and NO emissions for diesel and diesel- NOME measured mixtures. Finally, the test results were analyzed and compared with diesel fuel.

III.

\section{RESULTS AND DISCUSSION}

3.2 Transesterification of sesame oil 3.2.1 Effect of molar ratio of oil / methanol

The oil, alcohol molar ratio is one of the most important factors. The conversion of transesterification of the sesame oil to biodiesel Methanol sis sesame oil with the catalyst concentration of $1.0 \%$ by weight of oil at $60{ }^{\circ} \mathrm{C}$ with vigorous stirring and various oil / methanol molar ratio of 1:6, for example 1:4.5 1:09 01:12 is performed, and the results are shown in FIG .. Other

Figure 2: Conversion of sesame oil in different oil / methanol molar ratio [reaction temperature biodiesel. $60 \square$ $\mathrm{C}$ catalyst concentration of $1 \%$ by weight of the oil, and reaction time 90 minutes under reflux with vigorous stirring].

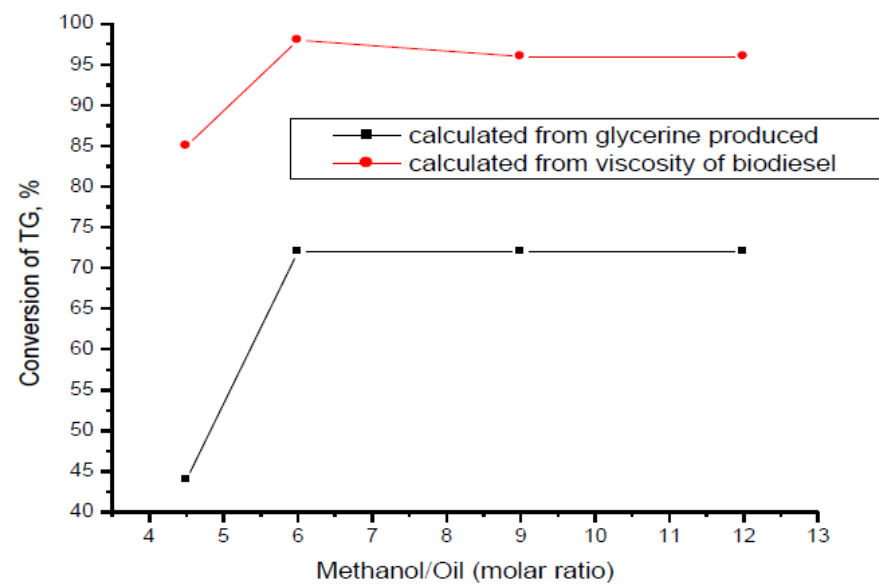

Figure 2 shows that the maximum conversion of sesame oil biodiesel oil / methanol molar ratio of 1:6 is found after 90 minutes, the conversion was $98.0 \%$, based on the kinematic viscosity, and $72 \%$ in the form of glycerol concentration. For both methods, the trends for the same oil methanol molar conversion are right. In the case of a molar ratio of 1: 4.5, the reaction time was not sufficient to achieve the desired conversion. The high molar ratio of alcohol to sesame oil interferes with the separation of the glycerol, as an increase in solubility. If glycerin remains in solution, it helps to drive the equilibrium to the left rear lower yield of biodiesel.

\subsubsection{Effect the catalyst concentration in the transesterification}

The transformation of sesame oil into biodiesel is greatly influenced by the catalyst concentration. Biodiesel conversion was generated either by measuring the concentration of glycerol in the reaction, and the kinematic viscosity of the products produced are measured. $6: 1.5 \%$ by weight of the oil at $60{ }^{\circ} \mathrm{C}$ and the oil / 
methanol molar ratio of 1 - Methanolysis sesame oil was carried out with $\mathrm{NaOH}$ as catalyst in the concentration range of 0.25 . The results are shown in Fig. 3

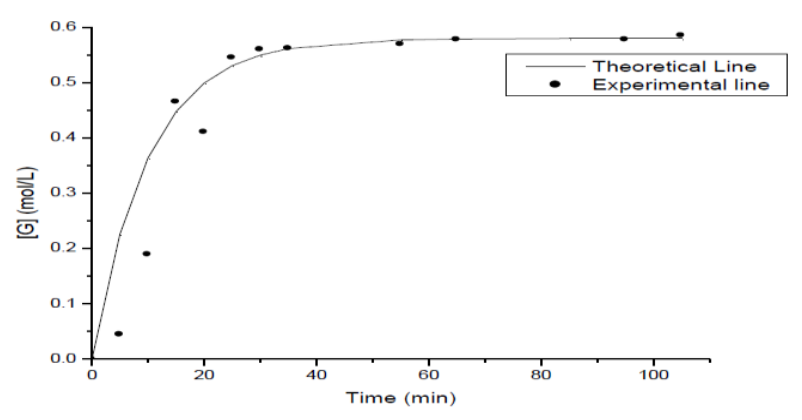

Figure 3: Conversion of sesame oil in different concentration of catalyst [reaction temperature biodiesel. $60^{\circ} \mathrm{C}$ Oil / methanol molar ratio of 1:6, a reaction time of 90 minutes under reflux with vigorous stirring] .

From the image. 3 shows that the lower catalyst concentration, i.e. $0.25 \% \mathrm{NaOH}$ minor oil to catalyze the conversion of sesame oil when biodiesel was measured in relation to the glycerol concentration and the conversion was $87.2 \%$ of the oil when the biodiesel . with respect to the measured kinematic viscosity But , $0.87 \mathrm{wt} \% \mathrm{NaOH}$ oil was optimal in the reaction both measurements with a conversion of $72 \%$ in the form of glycerol concentration and turnover of $98.3 \%$ with respect to the kinematic viscosity of only 90 minutes . With the increase in the concentration of the catalyst, it is reducing the yield of the methyl ester. This was consistent with the results of Dorado et al. (2004). And the formation of soap in the presence of large amounts of catalysts which increase the viscosity of the reactants and reduces the conversion. The reaction was found with triglyceride assay methods of glycerol are less than that which is determined by the viscosity method. It was expected lower conversion of the result because the significant amount of glycerin was lost during the separation of some of the glycerol and glycerol layer was the biodiesel layer.

Produced 3.4 Properties of Biodiesel

Properties of biodiesel produced and compared with biodiesel and petroleum diesel standard, are given in Table first

The quality of the biodiesel was determined by measurement of a property, such as cetane number, the ignition characteristics are determined. Cetane number of biodiesel was somewhat lower than the normal value of biodiesel. However, cetane number of mixing sesame oil with petroleum diesel was higher than the standard value of the bio-diesel. Flashpoint biodiesel was higher than petro - diesel that is safe for transport purposes [ 1]. Other properties, such as kinematic viscosity, cloud point, pour point, density, $\mathrm{pH}$ value , saponification, etc. measured .

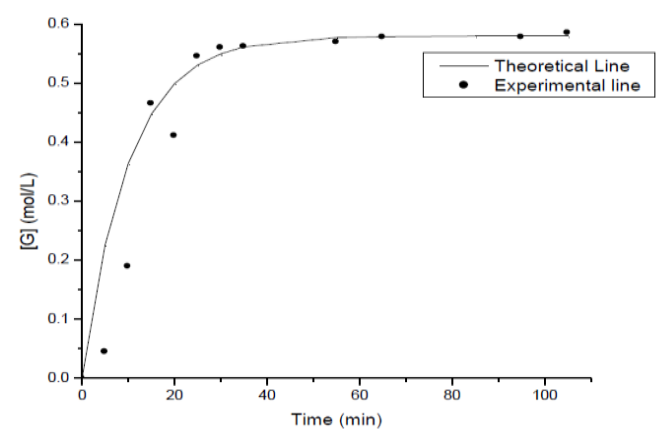

Figure 4: The concentration of the produced glycerol - time curve for transesterification .

\section{CONCLUSION}

Biodiesel from sesame oil synthesized by the base catalyzed transesterification . Raw Sesamöil, $2 \%$ FFA content. The properties of the crude oil were analyzed. Determines the optimum condition for the base catalyst transesterification. The optimal condition for the transesterification catalyst base was $0.86 \mathrm{wt} \% \mathrm{NaOH}$ to the oil as a catalyst, methanol / oil molar ratio of $6: 1$ and the maximum conversion was $98.57 \%$ oil to 90 minutes. A significant reduction in viscosity and acid number of biodiesel was found. The property such as density, viscosity, flash point, cloud point, pour point and calorific value is comparable to the standard value of biodiesel and petroleum diesel. Support the present experimental results show that biodiesel is successfully from sesame oil as a diesel. 


\section{FEEDBACK}

[1] Ando B Baglio S, S and Graziani Pitrone N (2000) models for Luftqualitätsmanagementund assessment . IEEE Trans. on Systems , Man and Cybernetics - Part C : Applications and Reviews. 30 (3), 358-363.

[2] Allen, CAW, Watts, KC, Ackman, RG , Pegg , MJ predict the viscosity of biodiesel from their ester composition. Fuel 199978 1319-1326.

[3] Bajpai , D.; Tyagi, U.K. Biodiesel : Source, production, composition, properties and its benefits. J. Oleo Sci . 2006, 55, 487-502.

[4] CJ Smith , J. Ross, treatment of fatty materials , U.S. Patent No. 2,383,580 (1945) .

[5] Chapman L (2007) Transport and climate change : a review . J. Transport Geography . 15 , 354-367 .

[6] Demirbas, A. relations physical properties of vegetable oil and biodiesel . Fuel 2008 87, 1743-1748 .

[7] Divya Bajpai ., Tyagi.V.K . (2006) Biodiesel : source, production composition, properties and its benefits.Jounal Fat Science, 55 (10): 487-502 .

[8] Duncan RC and Youngquist W (1999) encircles the peak of world oil production . Natural Res. Res. 8 , 219-232.

[9] El - Diwani , G., Attia , NK , Hawash , SI Development and evaluation of biodiesel and by-products from jatropha oil . Int . J. Environ. Sci . Technology . 2009 , 6, 219-224 .

[10] GB Bradshaw , New soap process, soap , 18 May ( 1942) 23-24, 69-70 .

[11] GB Bradshaw, toilet Meuly, the process of making pure soaps. U.S. Patent No. 2,271,619 (1942) .

[12] GB Bradshaw , toilet Meuly, the manufacture of detergents, U.S. Patent No. 2,360,844 ( 1944).

[13] Gattamaneni LNR , Subramani S, S and R Santhanam Kuderu (2008 ) combustion and emission characteristics in diesel engine with rice bran oil methyl ester and its diesel blends . Therm . Sci . 12 (1), 139-150 .

[14] Ghobadian B , Rahimi H, Nikbakht AM, Najafi G and Yusaf TF (2009) gas analysis Diesel engine performance and exhaust using waste cooking oil biodiesel with an artificial neural network . Renew. Energy. $34,976-982$.

[15] GG Pearl , animal fats potential for bioenergy Bioenergy 2002 Tenth Biennial Bioenergy Conference , Boise, ID , September 22 to 26, 2002.

[16] GuoqingGuan , Katsuki Kusakabe, Nozomi Sakurai, Kimiko Moriyama . (2009) transesterification of vegetable oil for fuel using acid catalysts in the presence of dimethyl ether biodiesel. Fuel , 88: 81-86

[17] Allen HD , WA Kline , methods for treatment of fatty oils , U.S. Patent No. 2,383,579 (1945) .

[18] Imahara , H., Minami , E., Saka, S. Thermodynamic study on cloud point of biodiesel with its fatty acid composition . Fuel $200685,1666-1670$.

[19] Percy JH , treatment of fatty acid glycerides, U.S. Patent No. 2,383,614 (1945) .

[20] J. Sheehan , V. Camobreco , J. Duffield, M. Graboski and H. Shapouri, Life Cycle Inventory of biodiesel and petroleum diesel for use in an urban bus, final report for the U.S. Office of Energy Development and fuel U.S. Department of Agriculture Office of Energy provided by the National Renewable Energy Laboratory, NREL / SR 580-24089 (May 1998).

[21] McCormick, RL, Ratcliff , M., Moens , L., Lawrence R. several factors that affect the stability of biodiesel in standard accelerated tests . Fuel Process. Technology . 2007, 88, 651-657 .

[22] Rashid , U., Anwar , F. Production of biodiesel through base - catalyzed transesterification of safflower oil with an optimized protocol . Energy Fuels 2008

[23] Rashid, U., Anwar, F., Moser, BR, Ashraf S. Production of sunflower oil methyl esters by optimized alkali-catalyzed methanolysis . Biomass Bioenergy 200832 , 1202-1205. 